\title{
O USO DE BLOGS COMO FERRAMENTA DE APOIO AO DESENVOLVIMENTO DA PRODUÇÃO ESCRITA EM LIINGUA INGLESA
}

\author{
THE USE OF BLOGS AS AN EDUCATIONAL TOOL FOR THE DEVELOPMENT OF \\ WRITING IN ENGLISH
}

Flávia Medianeira de Oliveira*

\begin{abstract}
RESUMO
O uso das Tecnologias Digitais de Informação e Comunicação no processo de ensino e aprendizagem de línguas se constitui como uma das alternativas na elaboração de práticas pedagógicas que visem tornar esse processo mais autônomo para aprendizes e professores. O uso das TDIC no âmbito educacional amplia não apenas as possibilidades de aprimoramento das principais habilidades linguísticas de recepção e produção oral e escrita, como também proporciona o desenvolvimento e a expansão da literacia digital. Este artigo relata uma experiência de ensino-aprendizagem em língua inglesa realizada com acadêmicos iniciantes de um Curso de Letras, visando oportunizar a esses aprendizes o desenvolvimento e o aprimoramento da habilidade escrita por meio da criação de um blog acadêmico. A pesquisa seguiu os pressupostos metodológicos da hermenêutica aplicada ao campo da pesquisa qualitativa, buscando identificar, analisar e interpretar não apenas o produto final, ou seja, as produções escritas, mas também como se deu esse processo. Os resultados sugerem que o uso do blog em um contexto real de ensino e de aprendizagem de línguas, com foco na formação docente inicial, foi bastante benéfica uma vez que oportunizou a construção de saberes e significados por meio da habilidade escrita. Por meio dessa experiência, os acadêmicos puderam desempenhar o papel de escritores autônomos, ou seja, tiveram a chance de escolher e discutir os temas que lhes interessavam, os gêneros textuais mais apropriados, fazer uso da multimodalidade e aprender a fazer uso das tecnologias digitais em prol de sua aprendizagem.

Palavras-chave: escrita; autonomia; blog; tecnologias; formação docente.
\end{abstract}

\section{ABSTRACT}

The use of Digital Information and Communication Technologies in the process of English teaching and learning has been one of the alternatives in the development of pedagogical activities that aim to strengthen teachers and learners' autonomy during this process. The use of DICT in the educational context collaborates not only for the enhancement of linguistic skills - listening, writing, speaking and reading -, but it also contributes for the improvement and the expansion of digital literacy. This article reports a teaching and learning experience in English carried out with first-year students from a Foreign Language Course, aiming at helping learners to develop writing abilities through the construction of an academic blog. The data was analyzed and interpreted based on the methodological conceptions of hermeneutics applied to the qualitative research, with the objective of identifying, analyzing and comprehending the final product, that is, the students' posts and the entire process behind it. The results suggest that the use of blogs in a real context of English teaching and learning, focusing on first-year students, had good effects once it promoted the development and improvement of writing skills. Through this experience, learners could act as autonomous writers, that is, they had the chance of choosing and discussing themes of their interest, the most appropriate textual genres, make use of multimodality and learn how to make use of digital technologies in the benefit of their learning. Keywords: writing; autonomy; blog; technologies; teacher education.

\section{INTRODUÇÃO}

As Tecnologias Digitais de Informação e Comunicação (TDIC) têm se tornado significativamente mais inovadoras e têm sido disponibilizadas a uma parcela cada vez maior da população'. Elas estão presentes em praticamente todos os contextos sociais, tais como comércio e governo eletrônicos, educação, prestação de serviços, entretenimento, turismo, relações pessoais, dentre outros.

No contexto educacional, as TDIC têm ocasionado diversas mudanças no que tange ao processo de ensino e de aprendizagem, uma vez que tanto aprendizes quanto educadores apresentam características diferentes daqueles de duas décadas atrás. Essa nova geração de alunos é denominada pelos pesquisadores de Geração 2.o (FIGUEIREDO, 2012; LEFFA, 2012), Geração Y (XAVIER, 2011) ou Net Geners (TAPSCOTT, 2008), sendo composta pelo que os autores chamam de 'nativos digitais', isto é, jovens que nasceram e cresceram junto com as tecnologias e que possuem completo domínio sobre o uso das mais diversas ferramentas digitais (telefones celulares, plataformas de jogos eletrônicos, aplicativos de música, fotos, redes sociais, etc.).

\footnotetext{
* Universidade Federal de Pelotas (UFPel), Pelotas, RS, Brasil. oliveira.flavia@ufpel.edu.br Orcid: https://orcid.org/0000-0001-9152-7243

1. Segundo relatório publicado pelo Comitê Gestor da Internet no Brasil (cgi.br), em 2018, 70\% dos brasileiros tiveram acesso à Internet (2019, p. 25).
} 
Essa nova geração de aprendizes tem exigido mudanças no modo como professores atuam no ensinoaprendizagem, especificamente no caso das línguas estrangeiras. No ensino superior, são minoria os alunos que ingressam no Curso de Letras com pouco ou nenhum conhecimento da língua e das TDIC, como evidenciam os estudos realizados por Rodrigues (2014) com estudantes ingressantes da Universidade Federal do Piauí no ano de 2011 e Berto (2018) com alunos da Universidade Federal Rural de Pernambuco.

Muitos aprendizes relatam que aprenderam pontos gramaticais ou conseguem falar o idioma porque fizeram uso das tecnologias como ferramenta de aprendizagem, tais como plataformas de jogos e vídeos, áudios, aplicativos de ensino e sites especializados. O levantamento realizado por Melo (2018) com alunos iniciantes da Universidade Federal da Paraíba constatou o uso de aplicativos (Duolingo, Snaptube, Wattpad, Lichess, dentre outros) e das redes sociais (Instagram, Facebook, YouTube, Pinterest) por esses estudantes como forma de aprender a língua espanhola antes de ingressarem no contexto acadêmico.

Desse modo, já não é mais possível utilizar apenas o material didático selecionado e nem tampouco fazer uso de computadores com acesso à Internet. Como reforça a literatura prévia, o professor precisa saber fazer uso de métodos ou abordagens de ensino-aprendizagem que visem incorporar as TDIC de modo efetivo e funcional, transformando seus aprendizes em sujeitos capazes de identificar suas estratégias e estilos de aprendizagem, de participar mais ativamente da construção de significados que estejam mais próximos de seus contextos reais e de serem capazes de utilizar as tecnologias como forma de adquirir, construir, transformar saberes fundamentais para sua formação enquanto aprendiz e cidadão do mundo.

Com base nessas considerações, este artigo relata uma experiência de ensino-aprendizagem de escrita em língua inglesa realizada com acadêmicos iniciantes do Curso de Licenciatura em Letras da Universidade Federal de Pelotas, no ano de 2018. O objetivo principal foi oportunizar a esses aprendizes o desenvolvimento e o aprimoramento da habilidade escrita por meio da criação de um blog, fazendo com que o processo de aprendizagem dessa habilidade fizesse realmente sentido para esses estudantes e estivesse bem próximo de suas experiências cotidianas.

Na próxima seção, apresento uma discussão teórica sobre a presença cada vez mais expressiva das TDIC no contexto de ensino e aprendizagem de línguas, abordo como as tecnologias podem auxiliar para tornar esse processo mais autônomo para aprendizes e professores e, por fim, discorro sobre como o gênero digital blog acadêmico pode ser utilizado como forma de desenvolver e aprimorar a habilidade escrita no âmbito do ensino superior.

\section{REFERENCIAL TEÓRICO}

Nos últimos trinta anos temos presenciado a contínua inserção das TDIC nos mais variados contextos sociais. $\mathrm{Na}$ última década, houve um acelerado crescimento no que diz respeito ao comércio eletrônico (Black Friday ${ }^{2}$, por exemplo), acesso maior da população a mídia digital de entretenimento (Youtube, Netflix, Spotify, Twitch, etc.) e a popularização das redes sociais (Facebook, Instagram, Twitter, LinkedIn, dentre outras).

No âmbito educacional, temos inúmeros relatos da literatura prévia (PAIVA, 2019; OLIVEIRA e SANTOS, 2018; THEISEN, 2015; SILVA e BRITO, 2013; MELO, 2012; FIGUEIREDO e CARDOSO, 2011; XAVIER, 2011; e TAPSCOTT, 2008) que exemplificam como as TDIC têm sido inseridas no processo de ensino e aprendizagem nas mais diversas áreas, promovendo mudanças nos procedimentos metodológicos e nos papeis desempenhados pelos aprendizes e professores. No caso das línguas estrangeiras, especialmente no ensino superior, essas mudanças são proporcionadas principalmente pelas peculiaridades da nova geração de alunos - Web 2.0 - e pelo tipo de formação profissional que esses aprendizes buscam.

No caso da língua inglesa, até duas décadas atrás, a maioria dos estudantes que iniciavam o curso de licenciatura possuía pouco ou nenhum conhecimento prévio do idioma, como mostra a pesquisa realizada por Basso (2001) com alunos iniciantes da Universidade Estadual do Paraná. Atualmente, uma parcela significativa dos alunos em formação inicial já possui um bom conhecimento no que se refere aos aspectos gramaticais e muitos já possuem bons níveis de proficiência oral na língua.

2. De acordo com o dicionário Cambridge, Black Friday diz respeito à sexta-feira seguinte ao dia de Ação de Graças quando as lojas reduzem o preço das mercadorias para atrair clientes que querem iniciar as compras natalinas. Essa ideia iniciou nos Estados Unidos e acabou se espalhando ao redor do mundo. Atualmente as compras são realizadas pela Internet. 
Esse perfil diferenciado de aprendizes é consequência da inserção cada vez maior das TDIC na vida desses jovens. Em meados dos anos de 1990, os recursos mais utilizadas no ensino e na aprendizagem de língua inglesa eram o dicionário, a gramática, o quadro negro, o retro projetor e o livro didático. A Internet começava a ser utilizada nos laboratórios das universidades como complemento no ensino, como evidenciam os estudos de Souza (1999) sobre o funcionamento de listas de discussão (mailing list) e grupos de discussão (newsgroups) por meio da Internet com a temática direcionada ao ensino de língua estrangeira; de Motta-Roth (2001) sobre o uso do programa ICQ33 (I Seek You) por graduandos do Curso de Letras na discussão de textos teóricos; de Paiva (2001) que fez uso do e-mail, de chats e da WWW para ministrar uma disciplina com foco na leitura e escrita também para graduandos do Curso de Letras; de Fonseca (2002) sobre as vantagens do uso de chats no ensino de línguas estrangeiras; e de Kerckhoff (2004) sobre o uso de blogs no processo de reflexão crítica de professores de línguas em formação.

No contexto atual, grande parte de nossos aprendizes ingressam no Curso de Letras com conhecimento em diversos tipos de tecnologias, a saber: smartphone, iPod e relógios digitais (BARBOSA e VASCONCELOS, 2018; MELO, 2018; SILVA e BRITO, 2013 e THEISEN, 2015). Além disso, eles possuem acesso à Internet ${ }^{4}$, às multimídias (e-book, rádio, TV, jogos, jornais, etc.) e a inúmeros aplicativos (WhatsApp, Instagram, Netflix, Snapchat, Duolingo, Facebook Messenger, para citar alguns).

O relatório publicado pelo Comitê Gestor da Internet no Brasil (2018, p. 123) exemplifica o acesso a esses recursos em números:

as atividades relacionadas a conteúdos multimídia continuaram sendo as mais frequentemente realizadas pelos usuários de Internet no país, depois das atividades de comunicação. Entre elas, ouvir músicas (73\%) e assistir a vídeos, programas, filmes ou séries on-line (73\%) foram as mais citadas pelos usuários de Internet. Outra atividade que merece destaque é jogar on-line, que passou de 27\%, em 2016, para $35 \%$, em 2018, o que representa um aumento de 15,3 milhões de usuários que realizaram essa atividade no período.

No que tange ao acesso as atividades relacionadas à educação e ao trabalho, o relatório (2018, p. 123) aponta que:

a mais citada foi realizar atividades ou pesquisas escolares, que, embora estável em relação 2017, apresentou uma redução significativa ao longo da série histórica, passando de 66\%, em 2008, para 42\%, em 2018. Além disso, estudar por conta própria pela Internet foi uma atividade realizada por $38 \%$ dos usuários, sendo mais comum entre aqueles na faixa etária de 16 a 24 anos (53\%), de classe A (60\%) e que possuem Ensino Superior (63\%).

Comparando as gerações de educandos, Figueiredo (2012, p. 82) destaca que "os nativos da Geração 1.0 'usam' as tecnologias como recurso, enquanto que os nativos da Geração 2.0 'vivem' nas tecnologias — o seu diaa-dia incorpora as tecnologias como algo de indissociável". Tapscott $(2008$, p. 3) acrescenta que cerca de 80\% da Geração 2.0 é mais ativa que a anterior, executando leituras interativas e realizando multitarefas ao mesmo tempo. Para o autor ${ }^{5}(2008$, p. 3), os aprendizes:

consideram o computador como mais do que uma ferramenta, como um lugar para se reunir com os amigos. Os espaços comuns em que eles se sentem seguros não estão no mundo físico, mas sim no mundo virtual, nas redes sociais como o Facebook. Ao contrário de se tornarem antissociais, a Geração Net está desenvolvendo um novo e amplo segmento de habilidades sociais.

Considerando essa inegável mudança no perfil de nossos acadêmicos e futuros docentes por conta dos constantes avanços sociais e culturais trazidos pela inclusão das TDIC no ambiente educacional, já não é mais possível pensar no ensino e na aprendizagem de línguas como um processo atrelado exclusivamente ao ponto de vista do professor e a/as metodologia/as selecionada/as por ele. Como aponta a literatura prévia (OLIVEIRA e SANTOS, 2018; DIAS, 2017; SILVA e BRITO, 2013; PÉREZ, 2012; TAPSCOTT, 2008; MIRANDA, 2007 e FREIRE, 1996), esse processo envolve também, cada vez mais, a participação, a compreensão e a conscientização que os próprios alunos têm sobre seus objetivos, suas necessidades e suas expectativas em relação à aprendizagem e à formação profissional.

3. Segundo Motta-Roth (2001, p. 179), ICQ é um programa de chat (conversa) que possibilita a vários usuários se conectar em um mesmo momento, estabelecendo um espaço virtual de reunião, onde todos podem inserir comentários escritos sobre o tema em discussão. A contribuição de cada participante vai aparecendo na tela de modo que todos possam 'participar da conversa'. Ao final da sessão, pode-se gravar e guardar o texto resultante da conversa.

4. De Acordo com o Comitê Gestor da Internet no Brasil (cgi.br), em 2018 a proporção chegou a $90 \%$ entre os jovens na faixa etária de 16 a 24 anos - o que indica que a Internet passou a ser elemento fundamental de socialização e ferramenta básica para aqueles que entram no mercado de trabalho.

5. Todas as traduções deste trabalho são de responsabilidade da autora. 
Sobre essa nova demanda, Tapscott (2008, p. 4) aponta que:

a educação não deve focar na transmissão de conhecimento e sim em ensinar aos estudantes como aprender. Os professores devem transformar suas aulas expositivas em orientações interativas e colaborativas, permitindo que os aprendizes explorem e descubram por si mesmos. As escolas devem usar computadores para o acesso individualizado e maximizar o tempo de uso do estudante.

Assim, a responsabilidade pelo desenvolvimento das habilidades e competências deve ser dividida entre o professor, os próprios aprendizes e a instituição a qual pertencem, permitindo que as partes envolvidas encontrem juntas maneiras de ensinar e aprender. O trabalho conjunto da tríade educacional, instituição-aluno-professor (CRUZ e BIZELLI, 2015, p. 81), é fundamental para que o processo de ensino e de aprendizagem se torne mais colaborativo, igualitário e emancipatório.

Há de se considerar também que um número expressivo de docentes pertence à Geração 1.0 com conhecimentos mais restritos em TDIC se comparada a Geração 2.0 (OLIVEIRA e SANTOS, 2018; AMIEL e AMARAL, 2013; SILVA e BRITO, 2013). Esse compartilhamento de informações e saberes transforma o ensino e a aprendizagem de línguas em um processo mais personalizado, participativo, significativo, mais próximo da realidade e do cotidiano de nossos acadêmicos.

Sobre essa co-responsabilidade, Freire (1996, p. 26) afirma que "os educandos vão se transformando em reais sujeitos da construção e da reconstrução do saber ensinado, ao lado do educador, igualmente sujeito do processo". $\mathrm{O}$ uso recorrente e efetivo das TDIC pode e deve colaborar para motivar e aproximar os alunos do mundo real, fora da sala de aula, fazer com que deixem de lado a passividade e assumam o papel de protagonistas de sua formação pessoal e profissional.

A Base Nacional Comum Curricular $(2017$, p. 9) destaca como um dos objetivos do ensino e da aprendizagem oportunizar aos alunos:

compreender, utilizar e criar tecnologias digitais de informação e comunicação de forma crítica, significativa, reflexiva e ética nas diversas práticas sociais (incluindo as escolares) para se comunicar, acessar e disseminar informações, produzir conhecimentos, resolver problemas e exercer protagonismo e autoria na vida pessoal e coletiva.

Nessa perspectiva, pesquisas têm evidenciado que o uso eficaz e bem planejado das TDIC no ensino de línguas contribui significativamente para o desenvolvimento da autonomia de nossos aprendizes (PAIVA, 2019; SILVA e BRITO, 2013; RAMOS, 2013; MELO, 2012; XAVIER, 2011 e TAPSCOTT, 2008). No contexto educacional, as TIDC têm sido usadas como forma de promover a co-responsabilidade no ensino de línguas, visando tornar os aprendizes mais autônomos, incentivando o trabalho individual e cooperativo, a divisão de tarefas, estimulando a resolução de problemas que realmente afetam seu contexto local e regional, impulsionando a criatividade, motivação e propiciando um ambiente de ensino e de aprendizagem interativo, com trocas de informações, opiniões, conhecimentos, experiências entre alunos e professores.

Para que isso ocorra efetivamente na prática, Silva e Brito (2013) apontam mudanças no perfil docente. Para os autores (2013, p. 120), um dos papeis essenciais dos educadores em relação ao desenvolvimento da autonomia deve ser a capacidade de propor atividades que visem "instigar seu aluno a querer saber mais, levando-o a aprender a ser crítico, questionador e autônomo".

No que tange à inserção das TDIC no âmbito escolar, Moran (2000) também destaca modificações na percepção e atuação docente. Nas palavras do autor (2000, p. 138), "a aquisição da informação, dos dados dependerá cada vez menos do professor. As tecnologias podem trazer hoje dados, imagens, resumos de forma rápida e atraente. O papel do professor - o papel principal - é ajudar o aluno a interpretar esses dados, a relacioná-los, a contextualizálos".

Essas novas demandas sociais e tecnológicas interferem no processo de ensino-aprendizagem e requerem do professor posturas diferentes em relação ao seu papel e as suas concepções teórico-metodológicas. Há, portanto, a necessidade de reflexão, revisão e, na maioria das vezes, adequação dos métodos de ensino e de aprendizagem por parte dos educadores. Como esclarece Paiva (2019, p. 22):

não basta dançarmos juntos os velhos ritmos, precisamos aprender a dançar novos ritmos. Isso não significa apagar os velhos hábitos, principalmente se eles ainda são eficientes, mas precisamos nos engajar em novas formas de aprender e de ensinar, de interagir e de colocar em circulação a produção de conhecimento. Cada vez mais, vamos ser demandados a nos fazer presentes em camadas digitais sobrepostas à estrutura física e alterar nossas ações de linguagem entre elas sem perder o foco de nenhuma delas. 
Nesse sentido, como ressalta Paiva (2019), "aprender a dançar novos ritmos", isto é, o desenvolvimento de novas formas de ensinar e de aprender, sem desconsiderar as anteriores, se constitui como uma tarefa primordial tanto para docentes quanto para aprendizes. Sobre essa necessidade, Melo (2012, p. 33) aponta para

a importância da criação de novos ambientes de aprendizagem mais ativos e interativos com recurso às TIC para aumentar a motivação, a criatividade, a autonomia, a partilha de saberes, fomentando o trabalho de grupo e a aprendizagem cooperativa e colaborativa, desenvolvendo nos alunos aptidões que se conformem às literacias exigidas ao exercício pleno de uma cidadania no Século XXI.

Também é importante salientar que tanto a educação básica quanto a educação superior devem ter como um de seus objetivos pedagógicos o combate à infoexclusão. A presença física das TDIC no contexto educacional por si só não garante aos aprendizes os saberes necessários para a inserção no mundo globalizado, no mercado de trabalho e, tampouco, para atuar minimamente em seu contexto local. Em outras palavras, mais do que propiciar o acesso às ferramentas tecnológicas, faz-se necessário abordar de que modo estas permeiam, influenciam, gerenciam, modificam o dia a dia de nossos educandos.

Silva e Pereira $(2011$, p. 3) enfatizam a necessidade de se pensar em uma abordagem pedagógica em que:

as fronteiras do acesso a informação e ao conhecimento não findam nas paredes das escolas, continuam em espaços sociais informais, com realce para os virtuais, sendo também espaços de desenvolvimento de múltiplas literacias. Assim, o impacto das TICs na educação não poderá ser dissociado do desenvolvimento das aptidões críticas de acesso, pesquisa, seleção, avaliação e reconfiguração da informação, permitindo uma movimentação ágil e fluente. Deste modo, o cerne do debate sobre a inclusão digital não é simplesmente o acesso, mas, sobretudo, a literacia digital.

O ensino de línguas aliado ao desenvolvimento e ao aprimoramento da literacia digital colabora não apenas para minizar a infoexclusão, como também para promover e desenvolver a autonomia dos aprendizes. Os dados do relatório do Cgibr (2018, p. 305) revelam que 67\% dos jovens entre 16 e 24 anos declararam não possuir habilidades para lidar com as TDIC. Destes, $72 \%$ pertencem às classes D e E e $40 \%$ cursaram o ensino superior.

Considerando essa problemática, as práticas docentes desenvolvidas no ensino superior, foco deste trabalho, devem enfatizar esses saberes em suas atividades pedagógicas como forma de complementar a formação acadêmica, preparando os alunos para atuarem em sociedades cada vez mais informatizadas e autônomas. No caso do Curso de Letras, é ainda mais primordial uma vez que estamos formando profissionais que atuarão como multiplicadores desses conhecimentos.

Leffa (2012, p. 401) argumenta que os fenômenos (acesso à informação, redes sociais, fim das fronteiras geográficas) resultantes do desenvolvimento das TDIC podem contribuir para tornar o aluno agente de sua própria aprendizagem. Benson e Huang (2008, p. 424) acrescentam que "o sucesso na aquisição de uma segunda língua depende do fato de os estudantes alcançarem e exercitarem algum grau de autonomia no que diz respeito ao seu aprendizado".

Nesse sentido, grande parte dos estudos (MELO, 2012; RAMOS, 2013; PAIVA, 2009 e 2010; BENSON e HUANG, 2008; BENSON, 2006; NUNAN, 2003; LITTLE, 2003 e DICKINSON, 1994) evidenciam duas palavraschave para a definição de autonomia no processo de ensino e de aprendizagem de línguas: decisão e responsabilidade. Dickinson (1994, p. 4), por exemplo, define como aluno autônomo aquele que se responsabiliza e é capaz de tomar as decisões necessárias em relação a seu próprio aprendizado. Nunan (2003, p. 193) acredita que aprendizes autônomos são aqueles capazes de desempenhar um papel ativo em seu próprio aprendizado.

Benson (2006, p. 1) descreve autonomia como:

a capacidade de se responsabilizar ou ter mais controle sobre sua própria aprendizagem em sala de aula e fora dela; especificamente no caso da aprendizagem de línguas, autonomia significa pessoas tendo mais controle sobre seus propósitos para aprender línguas e no modo como as aprendem. Autonomia envolve as habilidades e as atitudes que as pessoas possuem e que ainda podem vir a desenvolver.

À primeira vista, ambas as palavras estão relacionadas aos aprendizes que passam a ter a oportunidade de tomar decisões sobre seu próprio aprendizado dentro e fora da sala de aula e, do mesmo modo, são responsáveis por gerenciar esse aprendizado. Little $(2003$, p. 2) argumenta que "há um consenso de que a prática de autonomia do aluno requer discernimento, uma atitude positiva, capacidade de reflexão e predisposição para ser proativo ao interagir com outros aprendizes e ao gerenciar seu próprio aprendizado".

Entretanto, esses dois entendimentos - decisões e responsabilidade - também devem estar imbuídos nas concepções teórico-metodológicas do professor, uma vez que é ele quem proporciona, delimita, media e constrói 
conjuntamente com os educandos as condições para o aprendizado mais autônomo. Assim, nesse processo, o educador assume o papel de motivador, colaborador, mediador e interlocutor, enquanto ao aluno cabe o papel de aprendente proativo, colaborador, criativo, capaz de tomar decisões com base em seu senso crítico.

Esses apontamentos indicam a perspectiva de ensino e de aprendizagem autônomos precisa ser continuamente construída pelo professor e pelo aprendiz, levando em conta a metodologia, o currículo, as necessidades e expectativas dos educandos. Essa construção se faz indispensável uma vez que grande parte de nossos alunos é dependente das orientações e direcionamentos dos professores, têm dificuldades em tomar decisões por conta própria, correr riscos e em assumir comportamentos mais proativos no que diz respeito ao seu desenvolvimento e crescimento como aluno, como indivíduo e como ser social.

Autores como Little (1991), Dickinson (1994), Paiva (2009), Reinders e White (2016) ressaltam que o ensino da autonomia deve ser concebido como um dos objetivos da educação e que esse processo acontece a partir da ação cooperativa entre professor e alunos, buscando incentivar os aprendizes progressivamente a ter mais responsabilidades sobre seu próprio aprendizado. Para Dickinson (1994, p. 7), a "autonomia precisa ser ensinada e o professor tem o papel fundamental em auxiliar o estudante nesse processo de aprendizagem".

Nesse sentido, as TDIC se constituem uma das alternativas na elaboração de práticas pedagógicas que visem o desenvolvimento e/ou o fortalecimento da autonomia no ensino de línguas. O uso de computadores, da Internet e, mais recentemente, dos smartphones no âmbito educacional amplia não apenas as possibilidades de aprimoramento das principais habilidades linguísticas de recepção e produção oral e escrita, como também proporciona o desenvolvimento e a expansão da literacia digital.

Warschauer e Whittaker $(1997$, p. 27) destacam quatro benefícios do uso da Internet no ensino de línguas, a saber:

- A natureza linguística da comunicação online é vantajosa para promover o aprendizado da língua tendo em vista que o discurso eletrônico tende a ser lexicalmente e sintaticamente mais complexo do que o discurso oral,

- Proporciona condições favoráveis para a aprendizagem da produção escrita uma vez que se tem uma audiência autêntica.

- Aumenta a motivação dos estudantes; e

- Fomenta a ideia de que a literacia digital é essencial para o sucesso dos aprendizes; esse fato sugere que não é apenas uma questão de uso da Internet para aprender inglês, mas também o aprendizado de inglês deve funcionar bem na Internet.

Apesar das proposições de Warschauer e Whittaker terem sido apresentadas em meados dos anos de 1990, o último benefício descrito pelos autores evidencia que a questão teórico-metodológica e as especificidades do contexto digital ainda se constituem como as principais dificuldades para a elaboração e a execução de práticas pedagógicas que façam uso eficaz das TDIC no ensino de línguas. Na maioria dos casos, os docentes demonstram interesse e motivação, estão cientes das vantagens e da necessidade de inserção das tecnologias na sala de aula, mas alegam não ter conhecimento suficiente da metodologia mais adequada para seu contexto de ensino (OLIVEIRA e SANTOS, 2018; SILVA e BRITO, 2013).

Em muitos casos, em razão do desconhecimento, inexperiência ou comodismo, os professores fazem uso de softwares ou aplicativos educacionais sem levar em conta as especificidades do grupo de aprendizes que está atendendo. Moran (2000, p. 138) afirma que "avançaremos mais se soubermos adaptar os programas previstos às necessidades dos alunos, criando conexões com o cotidiano, com o inesperado, se transformarmos a sala de aula em uma comunidade de investigação".

Essa afirmação do autor evidencia que pesquisadores e professores não têm todas as respostas e nem 'receitas' prontas da melhor maneira para se trabalhar com as TDIC, mesmo porque essas ferramentas se modificam com rapidez assustadora. Em razão disso, a transformação da sala de aula em uma comunidade de investigação contribui para o desenvolvimento da autonomia dos aprendizes, aprimoramento das literacias digitais e capacitação docente no que diz respeito às tecnologias.

Ainda citando Warschauer e Whittaker (1997), esses autores também apontam que as TDIC proporcionam condições favoráveis para a aprendizagem da produção escrita. O uso efetivo dessa habilidade linguistico-discursiva 
é de extrema importância para a formação de nossos educandos, conforme ressaltam os documentos que regem o sistema educacional brasileiro.

De acordo com as Orientações Educacionais Complementares (BRASIL, 2002) e a Base Nacional Comum Curricular (BRASIL, 2017), o ensino-aprendizagem de língua estrangeira "[...] implica uma expansão do trabalho com escuta, oralidade, leitura e escrita de modo a propiciar vivências com textos discursivos, orais e escritos, relevantes para a atuação do/a estudante em espaços plurilíngues."

A maior dificuldade relacionada ao ensino e a aprendizagem da habilidade escrita diz respeito a falta de contextos autênticos, ou seja, as atividades de produção escrita propostas a nossos aprendizes simulam situações similares aos contextos reais (escrever e-mails, ensaios, resumos, sinopses de filmes, resenha crítica, para citar alguns exemplos).

As TDIC e, consequentemente, os gêneros digitais colaboram para tornar o desenvolvimento e aprimoramento dessa habilidade mais próxima da realidade de nossos alunos, haja vista que a Geração 2.0 utiliza diversas ferramentas e aplicativos para interagir e resolver problemas em seu dia a dia, tais como postagens em redes sociais (Facebook, WhatsApp, Instagram, Twitter), publicações e comentários em blogs e fórum de discussão, SMS, e-mail, dentre outros.

Os diversos documentos que têm regulamentado a educação básica e superior em nosso país destacam três pontos relevantes no ensino e na aprendizagem da língua inglesa: a) o desenvolvimento das habilidades de recepção e de produção escrita e oral, com foco na cooperação e no compartilhamento de informações e conhecimentos por meio da língua; b) a utilização da cultura digital e suas ferramentas e c) a proposição de práticas pedagógicas que aproximem os aprendizes dos contextos reais de atuação profissional e de vivência em sociedade.

Sobre o terceiro ponto, a BNCC explicita que (2017, p. 478):

é fundamental que sejam garantidas aos estudantes oportunidades de experienciar fazeres cada vez mais próximos das práticas da vida acadêmica, profissional, pública, cultural e pessoal e situações que demandem a articulação de conhecimentos, o planejamento de ações, a auto-organização e a negociação em relação a metas.

No caso da maioria de nossos aprendizes, a Geração 2.0, a inserção da cultura digital e dos gêneros textuais que dela se originam em sala de aula viabiliza aproximá-los de saberes e situações de interação já vivenciadas por eles no cotidiano e estimula a busca por novos conhecimentos, novas possibilidades de construir significados e de aprimorar suas habilidades linguístico-discursivas. Além disso, como ressalta a BNCC (2017, p. 478), "o acesso a saberes sobre o mundo digital e práticas da cultura digital não só possibilita maior apropriação técnica e crítica desses recursos, como também é determinante para uma aprendizagem significativa e autônoma pelos estudantes".

Especificamente no caso do desenvolvimento e aprimoramento da habilidade de escrita, Warschauer, Arada e Zheng (2010, p. 223) argumentam que "os educadores devem enxergar seus estudantes não apenas como aprendizes, mas também como reais escritores com alguma coisa importante para dizer e proporcionar a eles a oportunidade de escrever algo com uma finalidade definida e para uma audiência real por meio da mídia digital".

Levando em conta os aspectos mencionados pelos autores, os diversos gêneros digitais oriundos do contínuo e acelerado avanço das TDIC podem se constituir como alternativa para o ensino e a aprendizagem da produção escrita tanto na escola, quanto no contexto acadêmico. Essa prática pode servir como incentivo para que os aprendizes utilizem as ferramentas digitais não apenas para se comunicar, buscar informações ou se relacionarem socialmente, mas também para que possam aprender a pesquisar informações relevantes para sua formação, a interagir na língua alvo, a construir significados e pensamento crítico a partir de leituras, a produzir, publicar e comentar textos que expressem suas reflexões e opiniões, seus conhecimentos prévios, suas expectativas pessoais e profissionais.

Do mesmo modo, a produção escrita individual e coletiva deve ser vista como prática social, contribuindo para que os educandos aprendam a fazer escolhas, a se posicionar, a cooperar, a respeitar e tolerar diferentes pontos de vista, a refletir sobre a língua e cultura, exercendo a criatividade, a ética e a autonomia.

Diversos gêneros digitais oportunizam a prática da escrita (Twitter, fóruns de discussão, playlist comentada, posts, para citar alguns), potencializando a construção de sentidos em um contexto real e com uma finalidade definida. Os blogs são um exemplo de como os estudantes podem exercer a autoria individual ou coletiva, a criatividade, o protagonismo e a autonomia por meio de produções escritas que efetivamente refletem suas experiências de vida, ideias, seus interesses, suas expectativas em relação a si mesmo e aos outros, seus anseios, suas frustações e sentimentos. Gomes (2005, p. 313) sintetiza: 
ao constituírem espaços de publicação na web os blogs permitem tornar visível a produção escrita dos seus autores dando assim "voz" às suas ideias, interesses e pensamentos. Participar num blog que tenha uma audiência pode ser um estímulo à reflexão e produção escrita desde que exista uma orientação e acompanhamento nesse sentido.

Segundo Figueiredo e Cardoso (2011, p. 159), a utilização do blog em sala de aula é "uma estratégia pedagógica que conduz à existência de um ambiente onde aprender ganha significado, sendo a aprendizagem cada vez mais autônoma e respondendo aos diferentes interesses, motivações e ritmos de cada aluno".

Pérez (2012, p. 28) destaca dois aspectos benéficos para os aprendizes que participam de blogs, a motivação e a autonomia. Para a autora, "atividades motivadoras (com imagens, vídeos, sons, interatividade...) são um dos motores da aprendizagem". Com relação a autonomia, Pérez (2012, p. 30) afirma que:

promover a capacidade de aprendizagem autônoma é especialmente útil uma vez que a diversidade dos aprendizes supõe que existam alunos com interesses e formas de aprendizagem diferentes. Assim, os estudantes podem eleger entre os temas publicados aqueles que mais lhe interessam, assim como reforçar aquelas habilidades que possuem mais dificuldades, sendo eles próprios quem têm o poder de decisão.

Estudos prévios (KOZIKOSKI, 2007; MARCUSCHI, 2005 e GOMES, 2005), apontam que a utilização do primeiro blog se deu no ano de 1997 quando um programador de computadores iniciou a postagem de comentários pessoais sobre o conflito Israel-Palestina em seu website ${ }^{6}$. Esse gênero pode ser definido como uma ferramenta de comunicação assíncrona mediada pelo computador que pode ser facilmente criada, ajustada, mantida e frequentemente atualizada (NOYTIM, 2010). Segundo o autor, os maiores atrativos dos blogs são o acesso a uma tecnologia gratuita e de fácil manuseio e a multimodalidade que permite a inclusão de textos, cores, imagens, áudios, vídeos e links de sites de interesse do autor.

Mais especificamente, os blogs funcionam como diários online em que um indivíduo ou um grupo de indivíduos posta, edita, comenta e atualiza informações continuamente em ordem cronológica, compartilhando sentimentos, opiniões, reflexões, crenças, mensagens, textos de outrem, etc. (DIAS, 2017; PÉREZ, 2012; FIGUEIREDO e CARDOSO, 2011; ARAÚJO, 2009; MARCUSCHI, 2005 e CAMPBELL, 2003).

No âmbito do ensino de inglês como segunda língua, Campbell (2003, p. 2) aponta que os blogs podem ser categorizados em três tipos:

- Blog do tutor: gerenciado pelo professor e direcionado aos aprendizes;

- Blog do aprendiz: gerenciado por um aprendiz ou por um grupo pequeno de aprendizes. No caso do ensino de línguas esse tipo de blog é a melhor opção para desenvolver as habilidades de leitura e escrita.

- Blog da turma: resultado do trabalho colaborativo de um grupo maior de aprendizes.

No caso de acadêmicos iniciantes das licenciaturas, acredito que a criação de blogs da turma pode ser mais eficiente haja vista que a maioria dos aprendizes não tem experiências prévias com o uso de TDIC no contexto educacional, apenas para uso pessoal. A utilização de modo coletivo contribui para a aproximação e a comunicação mais eficiente entre estudantes e docentes, estimulando o trabalho colaborativo, a reflexão sobre as questões linguísticas e sobre novas formas de aprendizagem. Pérez (2012, p. 28) argumenta que

os docentes podem utilizar os blogs para se aproximar dos estudantes de uma forma nova e atrativa sem ter que limitar a interação exclusivamente a aula. É possível publicar materiais de maneira imediata e permitir o acesso à informações ou recursos necessários para a realização de projetos e atividades pedagógicas, otimizando assim o tempo de aula. Ademais, oferece aos estudantes a possibilidade de melhorar os conteúdos acadêmicos, enriquecendo-os com diversos elementos, tais como vídeos, áudios, imagens, jogos, etc.

Outro ponto positivo citado por Figueiredo e Cardoso (2011, p. 159) é o fato de que a construção de um blog co-responsabiliza o aluno no processo de aprendizagem e faculta a interação com pessoas e tarefas reais. Além de contribuir para o desenvolvimento individual dos aprendizes, a utilização desse gênero digital também permite

6. Kozikoski (2007, p. 16) salienta que a origem do blog é um assunto que causa certo debate. Para alguns autores o termo web blog foi usado primeiramente por Barger (1997) e a versão abreviada, por Merholz, em 1999. Houve uma explosão no crescimento do número de blogs quando a primeira ferramenta para construção dessa interface foi disponibilizada gratuitamente em meados de 1999: o serviço de publicação Blogger.com. Por outro lado, há os que clamam que, o uso do blog realmente começou em 1992, com o primeiro web site no qual Tim Berners-Lee atualizava uma lista de páginas acessíveis na internet. No entanto, esse site não se aproxima da noção de um blog como a conhecemos hoje em dia, e por essa razão, segundo Blood (2000), não podemos nos referir aos blogs, como os conhecemos, até a aparição de Scripting News Website, de David Winer, em abril de 1997. 
que professores formadores propiciem meios para que acadêmicos em formação inicial e continuada vivenciem essas práticas e possam multiplicá-las futuramente em seus contextos profissionais (DIAS, 2017).

A seguir, descrevo como se deu a criação do blog, quem eram os participantes e as práticas pedagógicas desenvolvidas nesse projeto.

\section{METODOLOGIA}

A ideia da criação de um blog para um grupo de alunos do primeiro semestre do Curso de Letras surgiu a partir da dificuldade em propor atividades de produção escrita que realmente fizessem sentido para aquele grupo, uma vez que os exercícios apresentados pelo material didático em uso continham temáticas muito distantes da realidade dos alunos, contribuindo para o desinteresse, falta de motivação e distúrbios em sala de aula.

Outra razão foi a percepção de que as TDIC eram pouco utilizadas no contexto acadêmico. Observou-se que o grupo de aprendizes demonstrava interesse e expectativas em relação ao uso de computadores e da Internet. Essa prática poderia contribuir não apenas para motivá-los na produção escrita, como também ensiná-los a utilizar ferramentas digitais no ensino e na aprendizagem de línguas, levando em conta que se trata de um curso de formação de professores.

O grupo era composto por 8 estudantes (4 do sexo feminino e 4 do masculino), com idade entre 17 e 25 anos. Desses 8, 4 alunos possuíam nível básico na língua e 4 possuíam nível pré-intermediário. A disciplina de Língua Inglesa 1 possui 10 horas de aula semanalmente. Dessas 10 semanais, 2 horas foram utilizadas para a elaboração e publicação das atividades de escrita no blog. Todos os alunos deveriam realizar postagens individuais ou em duplas uma vez que suas produções contariam para a avaliação final da disciplina.

O objetivo desse trabalho é relatar essa experiência de ensino e aprendizagem experienciada pela docente e pelos estudantes com o intuito de compreender não apenas o produto final, ou seja, as produções escritas, mas também como se deu esse processo. Assim, busquei identificar, analisar e interpretar em que medida a intervenção proposta fora benéfica aos aprendizes envolvidos, atingindo suas expectativas, colaborando para o desenvolvimento da autonomia e da formação inicial.

Nesse sentido, essa pesquisa seguiu os pressupostos metodológicos da hermenêutica aplicada ao campo da pesquisa qualitativa. Sidi e Conte (2017, p. 1945) afirmam que

a hermenêutica busca uma reflexão e uma compreensão sobre aquilo que vemos, lemos, vivenciamos, criando uma cultura imersa em diferentes tradições e experiências. Implica também na forma como realizamos o movimento para nos (re)conhecer a partir das experiências no mundo, ou seja, na medida em que interpretamos algo, relacionamos diretamente com a visão de mundo que temos, advindas de nossas experiências anteriores.

Sendo assim, busquei interpretar por meio da linguagem os dados provenientes das postagens dos aprendizes no blog criado, visando compreender e refletir sobre essa experiência vivenciada em minha prática docente e identificar quais aspectos desse processo foram positivos e quais foram negativos e o que poderia ser repetido futuramente. Side e Conte (2017, p. 1946) afirmam que "a hermenêutica relaciona-se diretamente com interpretação e com a compreensão dos fenômenos, das atitudes e dos comportamentos humanos, dos textos e das palavras".

Macedo, Kublikowski e Grandesso (2004, p. 86) complementam essa afirmação ressaltando que "por meio da linguagem é construída uma realidade compartilhada, traduzida em narrativas, que se posicionam de forma circular entre um indivíduo ou comunidade e os ideais culturais". Ainda segundo os autores (2004, p. 86), "a hermenêutica refere-se à compreensão do pesquisador desse duplo processo de interpretação, pelo qual o si mesmo se compreende e abre-se à interpretação do outro".

\section{SÃO GONÇALO MAGAZINE BLOG}

O blog São Gonçalo Magazine? foi criado na metade do primeiro semestre do ano de 2018. Os alunos já haviam cursado metade da disciplina de Língua Inglesa 1 e demonstravam desinteresse e frustração com as atividades pedagógicas apresentadas pelo material didático, especialmente naquelas direcionadas à habilidade de escrita. A

7. Endereço eletrônico: https://saogoncalomagazine.blogspot.com/p/clc.html 
proposta de criação do blog partiu da docente e teve a aceitação imediata dos aprendizes, uma vez que estes se sentiram motivados e desafiados.

O gênero blog foi escolhido em razão da facilidade de acesso às ferramentas digitais disponíveis na instituição, computador e Internet, que permitiriam o acesso a informações, tais como textos, vídeos, imagens e áudios em língua inglesa. Além disso, esse gênero possibilita a construção, o compartilhamento e a postagem de conteúdos escritos e orais de modo rápido e interativo. Também permite que os participantes interajam na língua alvo por meio da postagem de comentários assíncronos.

A Figura 1 apresenta a página inicial do blog com informações acerca dos alunos.
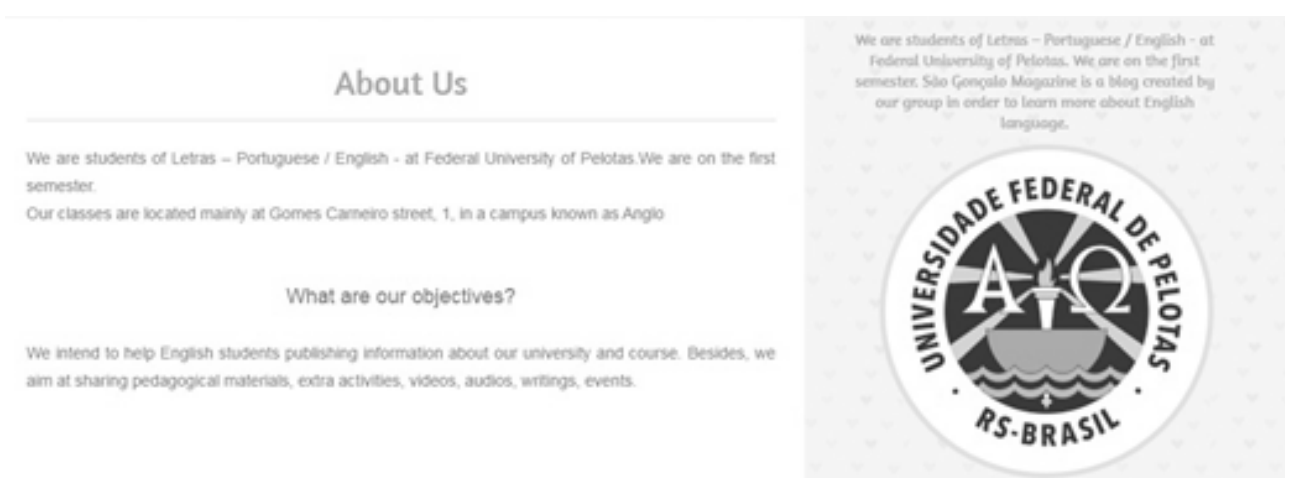

Figura 1. página inicial do blog São Gonçalo Magazine

No exemplo da Figura 1 é possível observar a preocupação dos aprendizes em evidenciar sua identidade e os objetivos da criação do blog. No lado direito da tela inicial está posicionado em destaque o logotipo da instituição, valorizando o contexto educacional a qual pertencem. Além disso, os objetivos mostram que as postagens têm como foco o cotidiano acadêmico dos estudantes e aspectos relacionados à sua formação profissional. Em uma pesquisa semelhante, Reinders e White (2016) constataram que participação de em um blog proporcionou aos aprendizes envolvidos a sensação de pertencimento, com o compartilhamento e trocas de perspectivas culturais.

A temática e o layout do blog, incluindo o próprio nome, foi inteiramente de responsabilidade dos 8 alunos envolvidos. Os temas escolhidos pelos aprendizes podem ser divididos em três eixos: a) informações relacionadas ao Curso de Letras e ao universo acadêmico da instituição; b) informações relacionadas à Copa do Mundo, evento que ocorreu durante aquele período e c) textos, músicas e conteúdos gramaticais trabalhados durante o semestre.

Reinders e White $(2016,148)$ relatam estudos prévios que afirmam que

os tipos de experiências disponíveis por meio da aprendizagem colaborativa na internet - incluindo as decisões dos aprendizes tomam sobre o tópico das trocas cooperativas; a natureza, a dimensão e a ênfase do feedback e da correção; o equilíbrio entre as atividades de conversação e o feedback dos pares foram identificados como modos pelos quais os educandos desenvolvem e exercitam autonomia em seu processo de aprendizagem da língua. A responsabilidade requerida dos aprendizes em relação ao seu próprio aprendizado e a natureza da aprendizagem foi vista como o produto de um processo colaborativo interdependente.

A Figura 2 exemplifica a primeira dessas temáticas. 


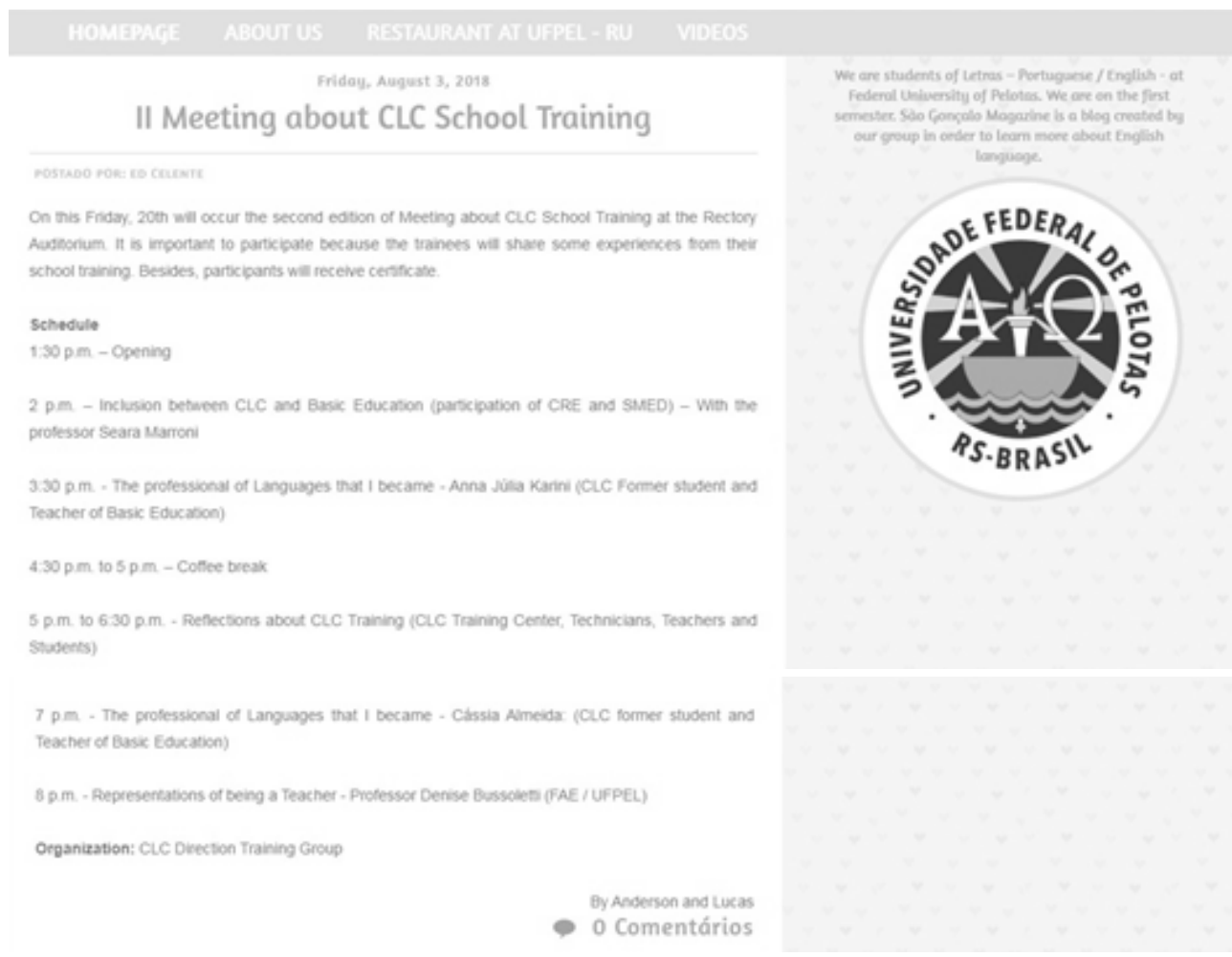

Figura 2. postagem sobre evento no Curso de Letras

A Figura 2 apresenta a postagem de um dos eventos do Curso sobre formação - encontro de estagiários que ocorreria no mês de agosto. Os alunos descrevem detalhadamente o cronograma de atividades, dando ênfase à relevância da participação dos demais aprendizes como mostra a sentença "it is important to participate because the trainees will share some experiences from their school training".

Na Figura 3, há outra postagem que evidencia a preocupação com a formação docente.

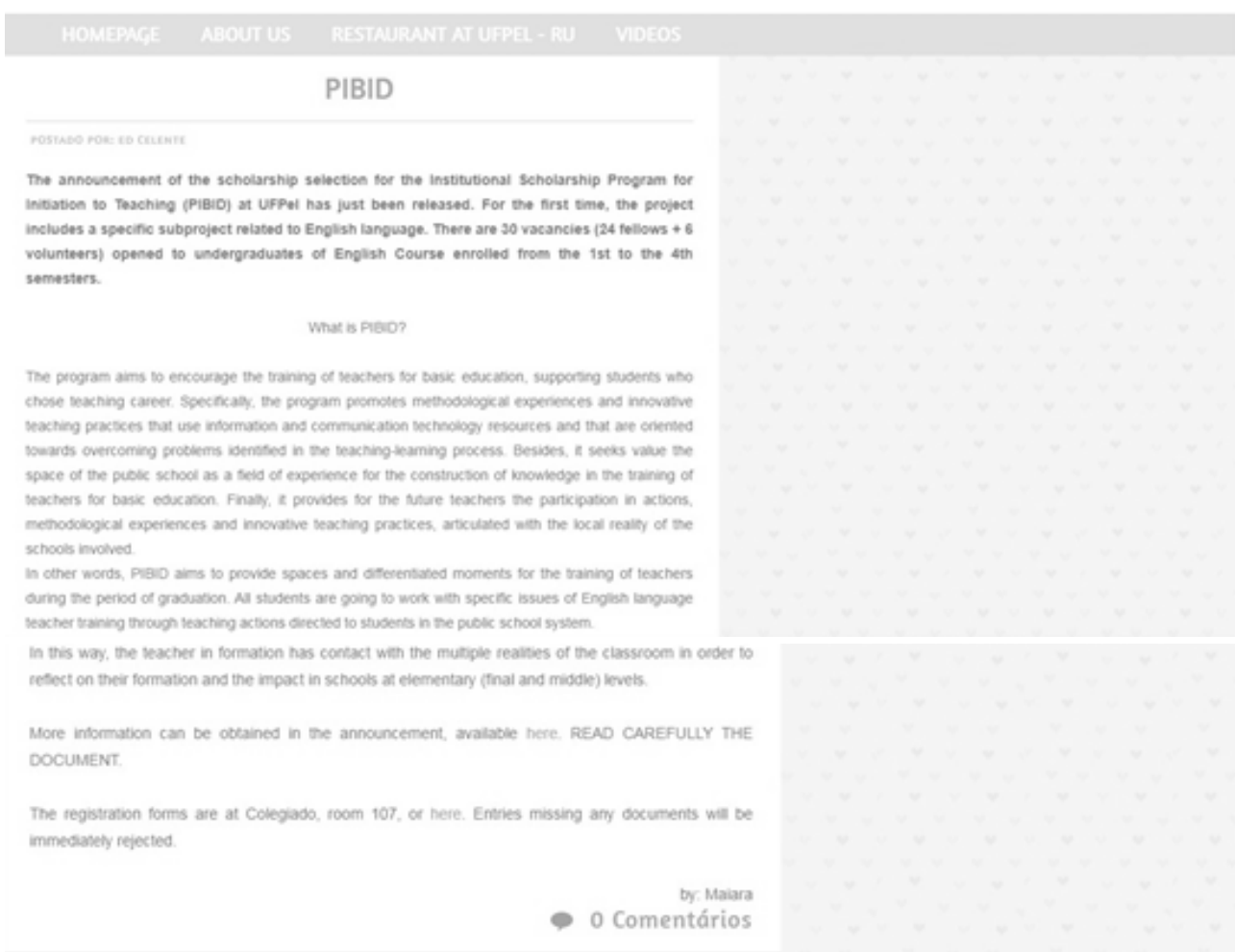

Figura 3. postagem relacionada ao PIBID 
Nesse exemplo, há um texto que apresenta aos demais estudantes do curso o Programa Institucional de Bolsa de Iniciação à Docência (PIBID). Novamente, há a preocupação em enfatizar atividades relacionadas à formação docente. Muito dessa preocupação se deve ao fato desses alunos participantes do blog já estarem atuando no contexto de ensino e de aprendizagem devido a sua inserção no PIBID.

$\mathrm{Na}$ Figura 4, visualizamos informações relacionadas à Copa do Mundo, a segunda temática escolhida pelos alunos.

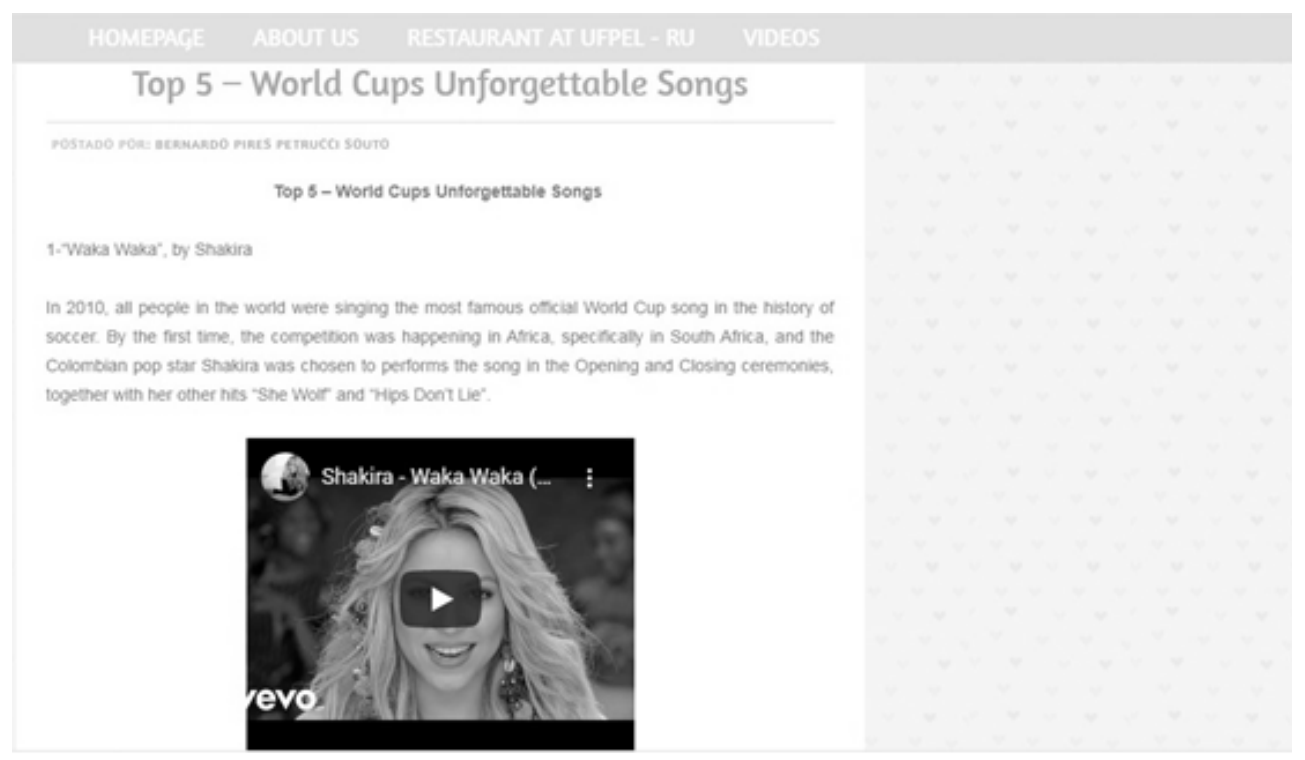

Figura 4. postagem sobre a Copa do Mundo de 2018

Nesse exemplo, os estudantes evidenciam a temática em voga naquele momento, a Copa do Mundo de 2018, assunto que interessava a todos os participantes do blog. Em decisão conjunta, cada um deles realizou uma postagem que compartilhasse alguma informação sobre o evento mundial. Sobre as possibilidades trazidas pelos blogs, Kozikoski (2007, p. 18) acrescenta que:

os blogs têm emergido como um meio de: informar um internauta sobre itens de interesse do autor e do próprio leitor; divulgar notícias e informações pessoais, bem como promover um interrelacionamento, por meio dos links que podem ser dispostos na interface. Essa troca de experiências, conceitos, pensamentos e opiniões, estabelece um canal informal de comunicação e abre um espaço de conversação e relacionamento muito amplo.

Ainda no caso da Figura 4, o aluno fez uso de um texto multimodal (linguagem verbal + áudio + imagem), evidenciando uma das características da Geração 2.0 - a capacidade de interpretar e fazer uso da multimídia. Segundo Tapscott (2009, p. 3), os Net Geners são muito melhores no que diz respeito à percepção visual e coordenação motora das mãos, além de serem mais eficazes enquanto tomam decisões e colaboram com outros.

A utilização de diferentes modos de linguagem também remete a um dos objetivos descritos na BNCC (2017, p. 489) em relação ao ensino e a aprendizagem de línguas:

Mobilizar práticas de linguagem no universo digital, considerando as dimensões técnicas, críticas, criativas, éticas e estéticas, para expandir as formas de produzir sentidos, de engajar-se em práticas autorais e coletivas, e de aprender a aprender nos campos da ciência, cultura, trabalho, informação e vida pessoal e coletiva.

Nas Figuras 5 e 6, há exemplos da terceira temática - conteúdos gramaticais trabalhados durante o semestre. No primeiro caso, o aprendiz replica uma das atividades de escrita proposta pelo material didático - o uso do tempo verbal present continuous para descrever pinturas famosas ${ }^{8}$. O texto escrito pelo estudante foi revisado pela docente e reescrito pelo aluno. É possível observar que o tipo de atividade de escrita e seu objetivo foram instigadoras para que esse aluno a ponto de despertar o interesse em repeti-la no blog.

Outro aspecto importante é que a pintura famosa escolhida pelo aluno reflete a cultura brasileira enquanto no material didático a proposta de trabalho enfatiza a cultura britânica. O ponto de vista do aluno demonstra o interesse

8. Mr. and Mrs. Clark and Percy (1970-1971) by David Hockney 
em valorizar e construir significado sobre o contexto de cultura no qual está inserido. Kozikoski (2007, p. 29) salienta que nesse caso:

a escrita passa a ser vista, também, como um processo de significação que, para ocorrer, precisa reconhecer a importância da geração, formulação e refinamento das ideias. Essa visão implica comprometimento por parte do aluno; revisão e interferência do professor ao longo do processo e conscientização da existência de um leitor.

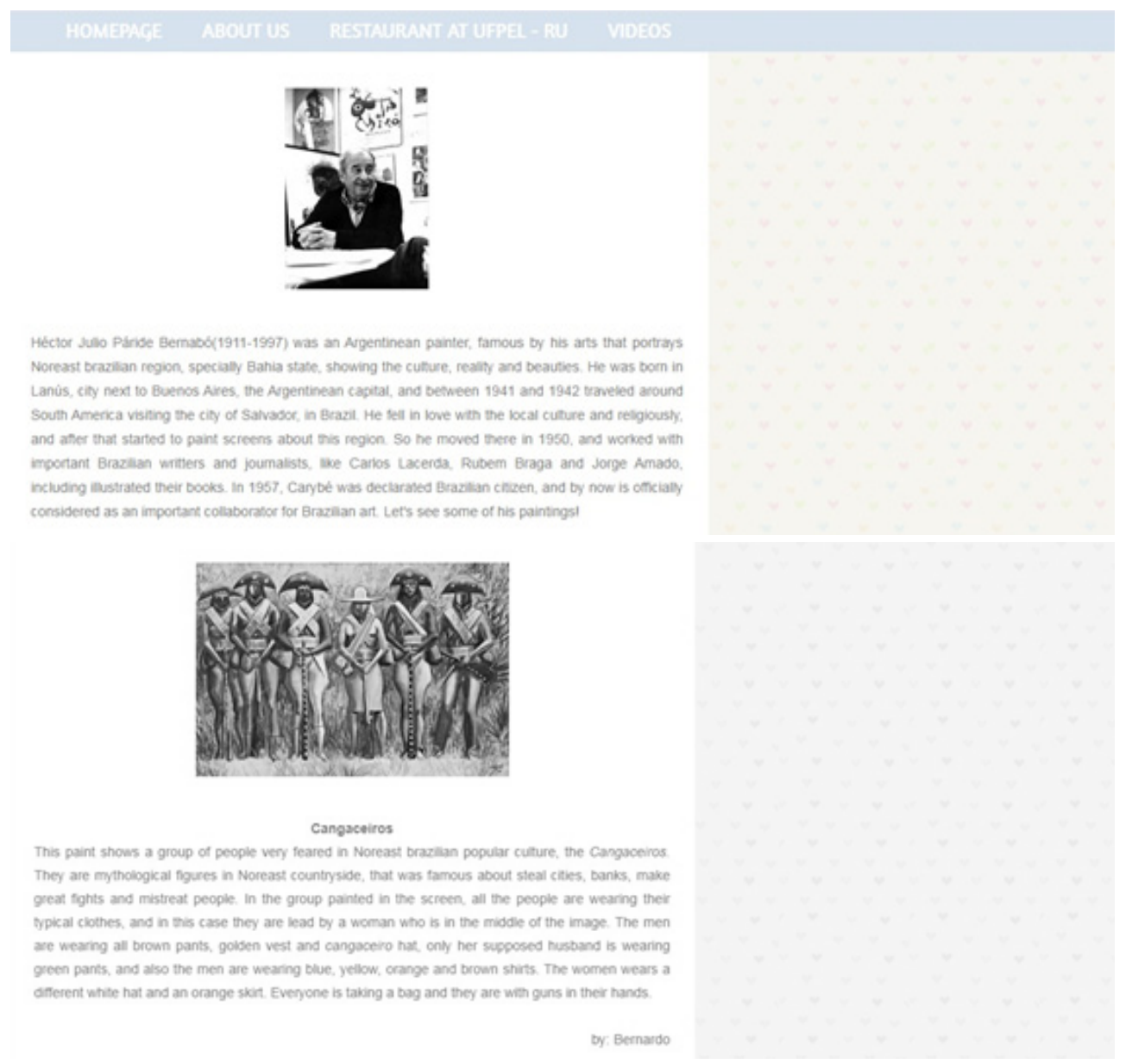

Figura 5. atividade de escrita com foco em aspectos gramaticais

A postagem da Figura 6 mostra novamente o interesse do aprendiz em demonstrar identidade enquanto acadêmica do Curso de Bacharelado em Tradução e futura profissional da área. O texto da estudante descreve informações do campo profissional com o intuito de valorizar sua área de atuação. Pérez (2012, p. 28) reforça que blogs oportunizam "o fomento de atividades em colaboração a que se somam contribuições individuais, o desenvolvimento da escrita para expressar opinião, experiências e como forma de impulsionar a criatividade e o debate". 


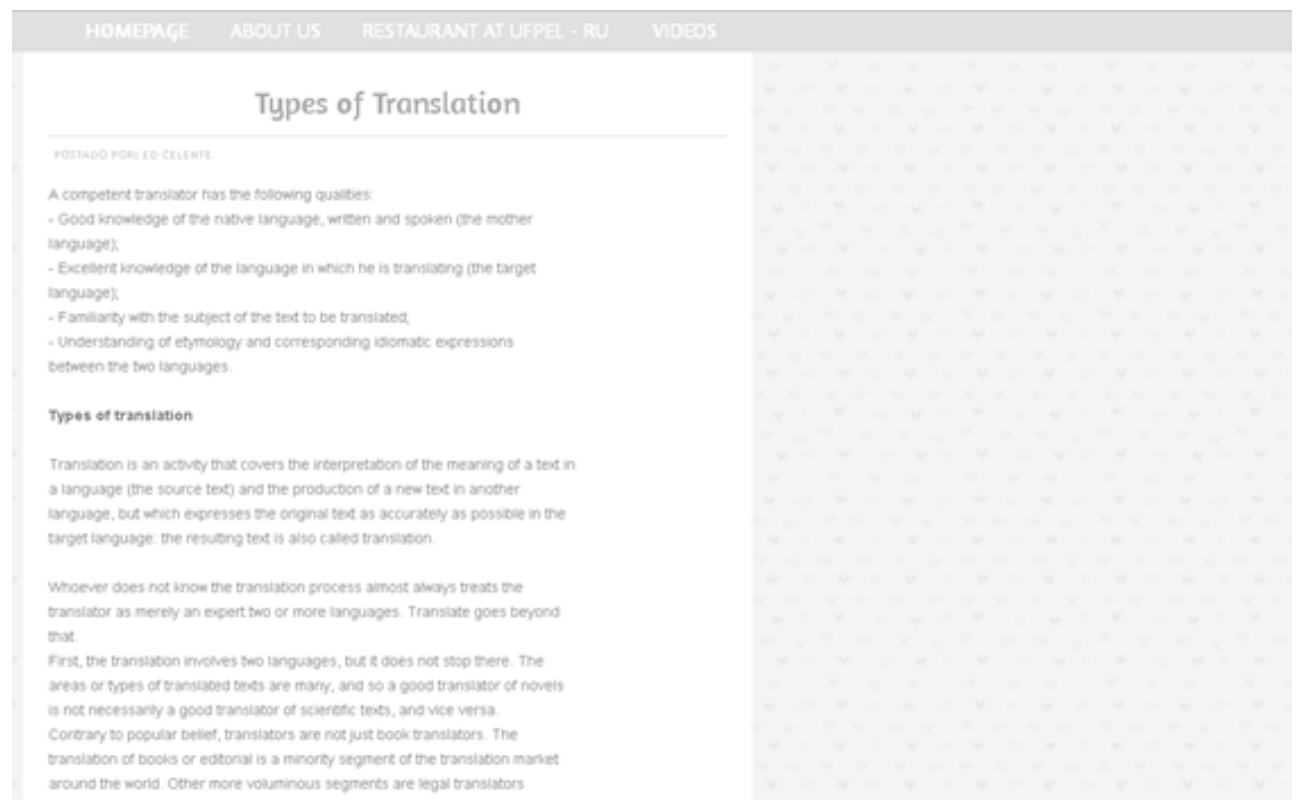

Figura 6. postagem sobre o Curso de Bacharelado em Tradução

No próximo exemplo, Figura 7, observa-se a postagem de dois vídeos com entrevistas realizadas pelos aprendizes. Essa atividade foi realizada em sala de aula após a turma receber a visita de duas professoras visitantes do Programa Inglês em Fronteiras, subsidiado pela instituição. Após o término das atividades, a docente sugeriu que uma delas poderia fazer parte do blog. Os estudantes então escolheram o gênero entrevista, elegendo um dos membros da turma para ocupar o papel de entrevistador. O tema da entrevista com as professoras visitantes teve o foco na experiência profissional das mesmas.

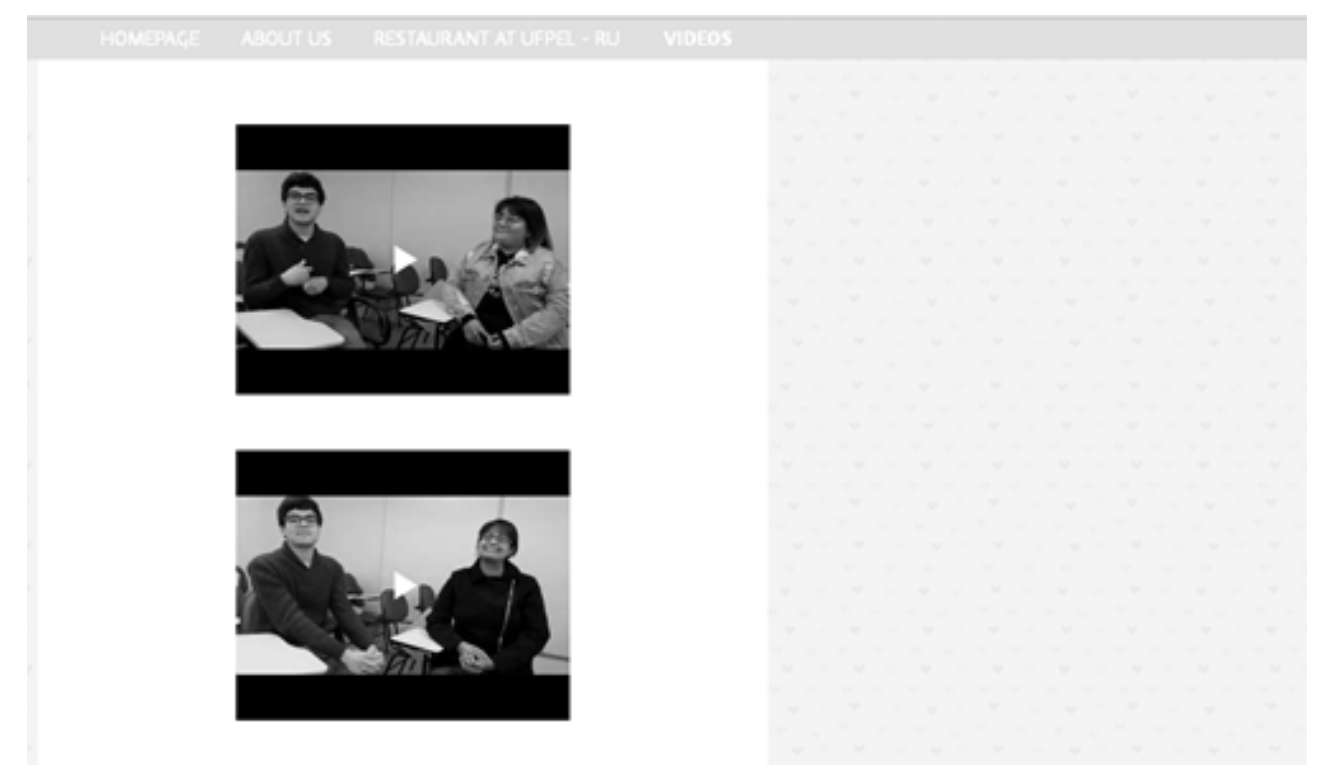

Figura 7. postagem dos vídeos com entrevistas

A realização dessa tarefa revelou significativa motivação e interesse por parte dos aprendizes que tiveram a oportunidade de experimentar outro modo de linguagem (HEMAIS, 2010) ao interagir, expressar suas ideias, pensamentos, expectativas e experiências. Novamente, é possível constatar o uso da multimodalidade por meio da criação e publicação do vídeo com a entrevista realizada.

Assim como Noytim comprovou em seu estudo, os estudantes buscaram tornar os blogs mais atrativos fazendo uso da multimodalidade (textos com fotos, desenhos, vídeos, acréscimo de links para informações extras), conforme mostram as Figuras 8 e 9. Segundo o autor (2010, p. 1131), essa possibilidade torna a atividade de escrita mais 
motivadora do que a escrita no papel em razão das inovações proporcionadas pela tecnologia, especialmente no caso da Geração 2.0.

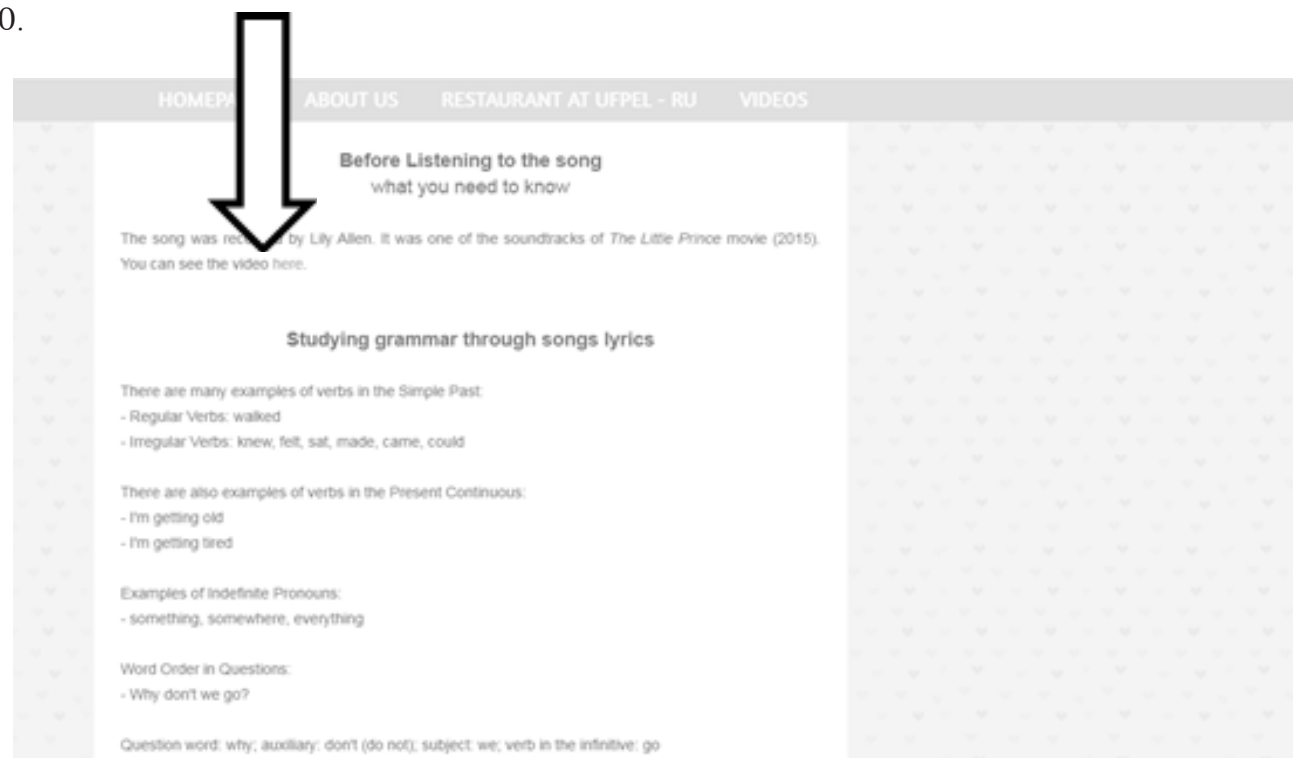

Figura 8. postagem de atividade gramatical

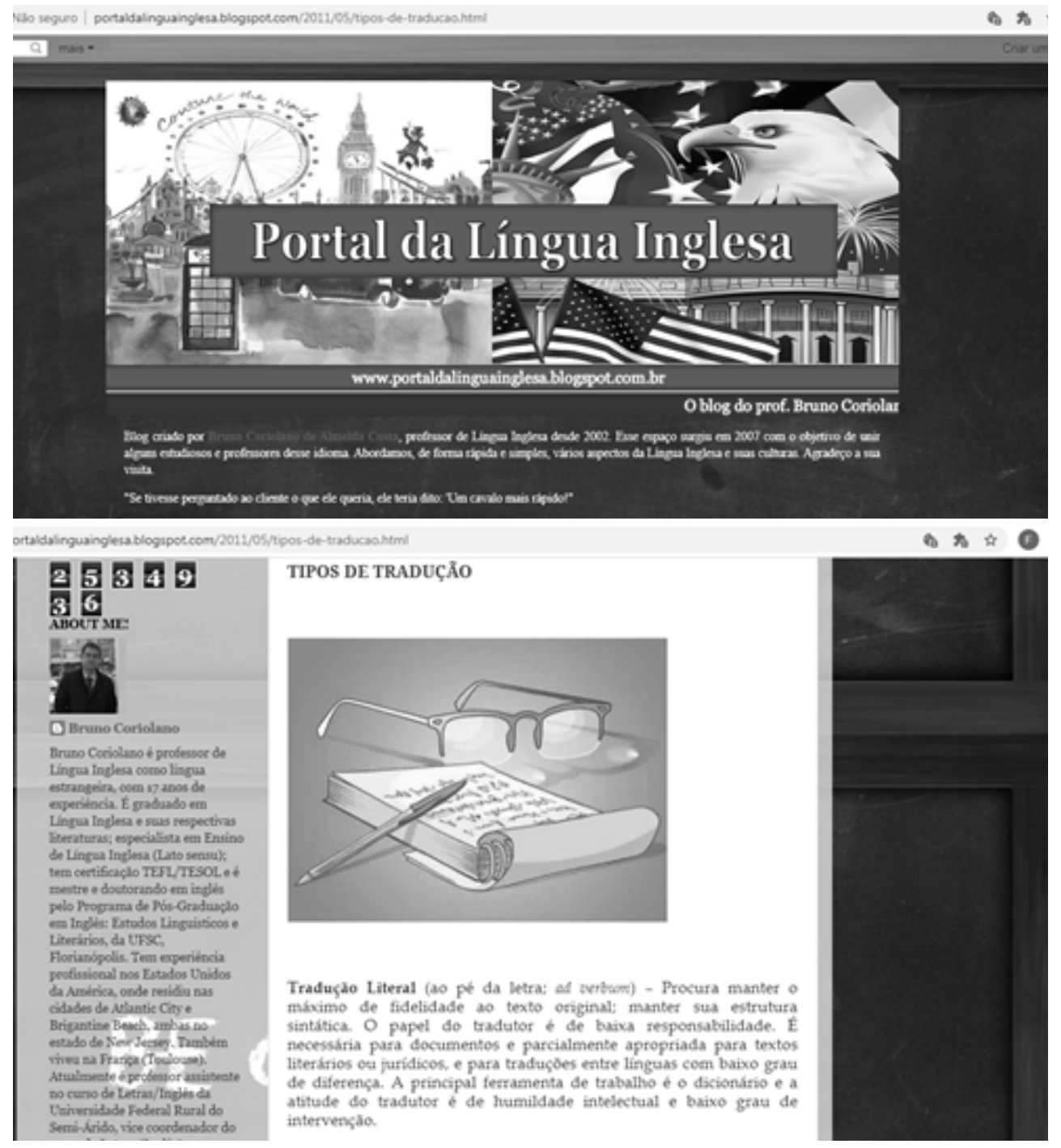

Figura 9. postagem de link com informações adicionais 
Na Figura 10, evidencia-se o papel desempenhado pela docente e pelos alunos da turma. Durante todo o período de desenvolvimento e postagem no blog, os aprendizes trabalharam de modo coletivo, decidindo em conjunto as temáticas e distribuindo tarefas. Por vezes, essas tarefas eram realizadas em duplas ou individualmente. Nesse caso, os alunos assumiram o papel de protagonistas, elaborando as atividades de escrita de acordo com seus interesses e prioridades e tomando para si a responsabilidade de postar as produções. Paiva (2001, p. 304) destaca que:

nas comunidades virtuais de aprendizagem, abandona-se o modelo de transmissão de informação tendo a figura do professor como o centro do processo e abre-se espaço para a construção social do conhecimento através de práticas colaborativas. Da mesma forma, o professor não é o único a sugerir fontes de informação ou a indicar tarefas. Há uma troca entre os aprendizes e o professor também aprende com os seus alunos.

A docente desempenhou o papel de mediadora, coordenando as discussões sobre as temáticas, orientando na busca por informações, sugerindo modos de publicações e revisando os textos produzidos. Na visão de Paiva (2001, p. 304), essas novas e necessárias posições assumidas pelos envolvidos no processo de ensino e de aprendizagem de línguas indicam que "os participantes, incluindo o professor, passam por um processo de aprendizagem ao mesmo tempo individual e coletiva que se dá através da interação e da negociação de sentidos com os outros e com o material com o qual também interagem".

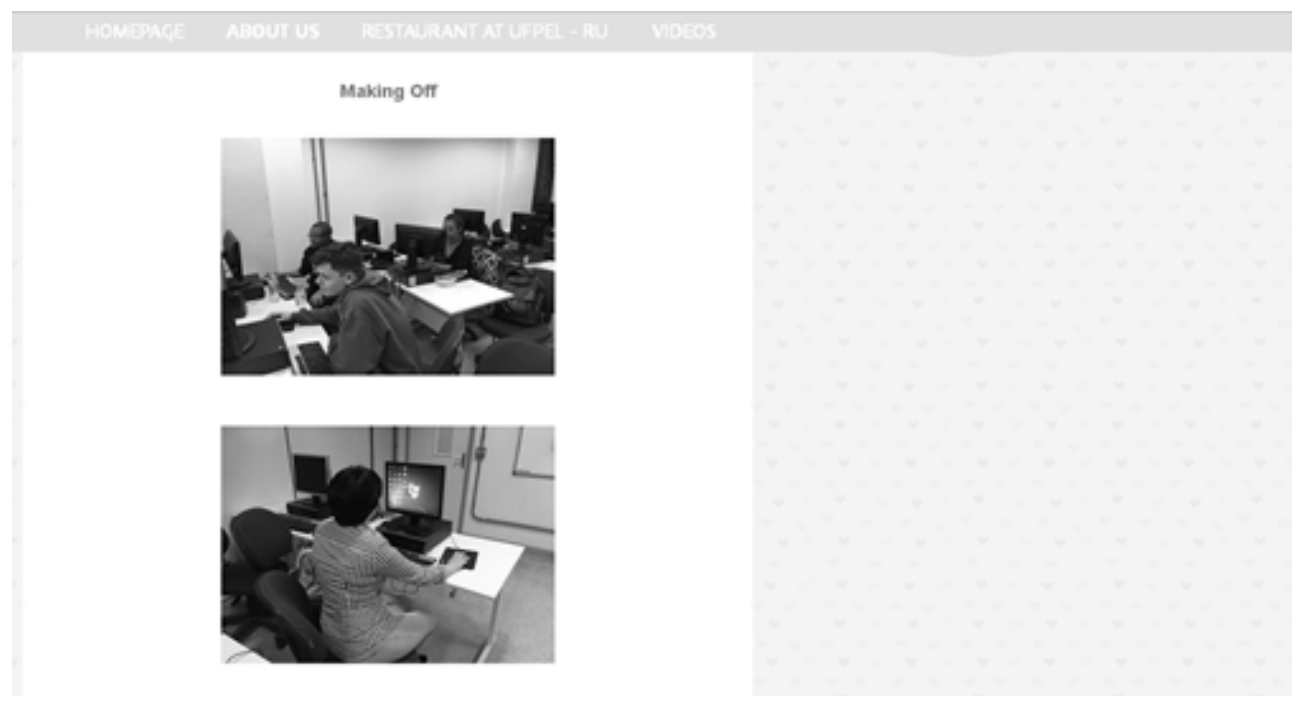

Figura 10. Docente e participantes do blog São Gonçalo Magazine em ação

Em suma, os exemplos aqui apresentados sugerem que a utilização do gênero digital blog em um contexto real de ensino e de aprendizagem de línguas, com foco na formação docente inicial, foi bastante benéfica aos aprendizes uma vez que oportunizou o desenvolvimento e aprimoramento da habilidade escrita. Por meio dessa experiência, os acadêmicos puderam desempenhar o papel de escritores autônomos, ou seja, tiveram a chance de escolher e discutir os temas que lhes interessavam e os gêneros textuais mais apropriados, fazer uso da multimodalidade e aprender a fazer uso das tecnologias digitais em prol de sua aprendizagem.

Entretanto, a experiência revelou um ponto negativo - a falta de comentários entre os participantes do blog. Nenhuma das postagens realizadas recebeu comentários por parte dos aprendizes. Creio que esse fato se deu por três motivos, a) tratar-se da primeira experiência com esse gênero tanto por parte dos alunos quanto pela docente; b) a preocupação dos aprendizes em produzir e publicar seus textos de modo efetivo uma vez que suas produções estavam sendo avaliadas e c) a falta de experiência para expressar seu pensamento crítico.

Os alunos demonstravam interesse em saber o que os demais estavam produzindo, questionando oralmente e dividindo as tarefas, mas não revelaram essa atitude, nem interagiram por meio do blog. Miranda $(2007$, p.44) afirma que a "integração inovadora das tecnologias exige um esforço de reflexão e de modificação de concepções e práticas de ensino. Alterar estes aspectos não é tarefa fácil, pois é necessário esforço, persistência e empenhamento".

Fica evidente que, nesse grupo de aprendizes, a aprendizagem colaborativa fez toda a diferença, contribuindo para os estudantes pudessem realizar escolhas, exercessem o papel de protagonistas de suas produções escritas, 
refletissem sobre questões linguísticas e de formação docente e fizessem uso das TDIC como um complemento a mais em sua aprendizagem e formação profissional.

Como ressaltam Oliveira e Souza $(2018$, p. 7):

Esse tipo de atuação proporciona formar professores com uma visão crítica frente às transformações globais que estruturam a realidade atual nos diferentes espaços de aprendizagem. A organização didática com o uso de gêneros digitais poderá, assim, nos trazer grandes contribuições para a profissionalização docente.

\section{CONSIDERAÇÕES FINAIS}

A intervenção pedagógica relatada nessa pesquisa exemplifica que inserção das TDIC no contexto de ensino e de aprendizagem pode se constituir como uma metodologia enriquecedora e motivadora, uma vez que aprendizes da Geração 2.0 precisam se sentir desafiados, instigados, influenciados durante o processo de aprendizagem. Não há mais espaço para metodologias unilaterais que visem abordar este ou aquele aspecto, muitas vezes desconsiderando as necessidades, pontos de vista, interesses, feedback, perspectivas de formação dos aprendizes.

É cada vez mais evidente que, quando bem planejada, fundamentada e organizada, a inserção das TDIC no ensino de línguas colabora para o desenvolvimento e aprimoramento das habilidades linguísticas, como evidenciou essa pesquisa em relação à produção escrita. As funcionalidades proporcionadas pelas tecnologias colaboram para a conexão dos aprendizes com as práticas reais de usos da linguagem.

A ênfase na abordagem dos gêneros digitais e da multimodalidade contribui para o letramento digital dos aprendizes, inserindo-os não apenas nas práticas sociais do contexto acadêmico (Skype, blogs educativos, formulários online, Google docs, podcasts, para citar alguns) como também do contexto profissional. Conforme ressalta Dias (2017, p. 94), "as práticas de letramento digital são fundamentais no processo de reflexão e, consequentemente, de formação (pessoal, acadêmica e profissional)".

O resultado final desse trabalho com o gênero digital blog revelou que mudanças no meio do percurso são necessárias a fim de que resultados mais eficazes possam ser alcançados. Assim como Kozikoski (2007, p. 27) constatou em seu estudo sobre o Google docs, a utilização do blog em meu contexto de ensino

proporcionou a interação entre os alunos, entre cada aluno consigo mesmo, entre os alunos e a máquina e entre os alunos e o meio, neste caso o meio digital proporcionado pela Internet, numa constante negociação de conceitos e significações que lhes permitiu o resgate e o aperfeiçoamento de um conhecimento já adquirido da língua inglesa e a aquisição de um novo conhecimento, o do universo dos blogs.

Por fim, acredito que o engajamento em atividades pedagógicas que promovam o trabalho em equipe, a resolução de problemas comuns, a tomada de decisões em conjunto, o exercício da reflexão crítica, a construção de significados recíproca, o protagonismo dos participantes oportuniza o desenvolvimento e a prática da autonomia, contribuindo para a formação de sujeitos/profissionais mais proativos, comprometidos, dispostos a interagir e a mediar, criativos, empreendedores e reflexivos.

\section{REFERÊNCIAS}

AMIEL, T.; AMARAL, S. F. (2013). Nativos e Imigrantes: questionando o conceito de fluência tecnológica docente. Revista Brasileira de Informática na Educação, v. 21, n. 3, p. 1-11.

ARAúuJO, M. C. M. (2009). Potencialidades do uso do blog em educação. Dissertação de Mestrado. Natal: Universidade Federal do Rio Grande do Norte.

BASSO, E. A. (2001). A construção social das competências necessárias ao professor de língua estrangeira: entre o real e o ideal um curso de Letras em estudo. Tese de Doutorado - Instituto de Estudos de Linguagem. Campinas, SP: Universidade Estadual de Campinas.

BARBOSA, I. M.; VASCONCELOS, C. R. D. (2018). O planejamento de ensino como estratégia para construção de conhecimento e otimização do tempo pedagógico. In: ALVES, I. M. A.; NETO, A. A. L. (Orgs.) O coordenador pedagógico em uma Educação a Distância sem distância. Salvador, BA: Edufba, p. 13-37. 
BARGER, J. (1997). Robot wisdom weblog for December 1997. Home Page. Disponível em: http://robotwisdom2.blogspot.com.

BENSON, P. (2006). Autonomy in language learning. Language Teaching, v. 40, n. 1, p. 21-40.

BENSON, P.; HUANG, J. (2008). Autonomy in the transition from foreign language learning to foreign language teaching. D.E.L.T.A, v. 24, p. $421-439$.

BERTO, F. L. (2018). Considerações sobre crenças de graduandos em Letras acerca do processo de aprendizagem de língua inglesa. Trabalho de Conclusão de Curso. Garanhuns, PE: Universidade Federal Rural de Pernambuco.

BLOOD, R. (2000). Weblogs: A History and Perspective. Rebecca's Pocket. 07 September 2000. Home Page. Disponível em: http:// www.rebeccablood.net/essays/weblog_history.html.

BRASIL. (2017). Ministério da Educação e Cultura. Base Nacional Comum Curricular. Educação Infantil e Ensino Fundamental. Disponível em: http://basenacionalcomum.mec.gov.br/wp-content/uploads/2018/02/bncc20dez-site.pdf. Acesso em: 26 jul. 2018.

BRASIL.(2002). Secretaria de Educação Média e Tecnológica. PCN + Ensino Médio: orientações educacionais complementares aos Parâmetros Curriculares Nacionais: linguagens, códigos e suas tecnologias. Brasília.

BRASIL. (2000). Secretaria de Educação Média e Tecnológica. Parâmetros Curriculares Nacionais: ensino médio. Brasília.

BUZATO, M. K. (2004). As (outras) quatro habilidades. The Four (Other) Skills. TE@D - Revista digital de tecnologia educacional e educação à distância, São Paulo, v. 1, p. 1-20.

CAMPBELL, A. P. (2003). Weblogs for use with ESL classes. The Internet TESL Journal, v. 9, n. 2.

Comitê Gestor da Internet no Brasil (CETIC.BR Tic Educação). (2018). Relatório. Disponível em: https://www.cetic.br/media/ docs/publicacoes/2/12225320191028tic_dom_2018_livro_eletronico.pdf. Acesso em: 23 de janeiro de 2020.

CRUZ, J. A. S.; BIZELLI, J. L. (2015). Docência para o ensino superior: inovação, informação e construção do conhecimento na era digital. Cad. Ed. Tec. Soc., v. 8, n. 1, p. 79-90.

DIAS, S. M. A. (2017). O blog reflexivo no processo de letramento e formação de professores de língua inglesa. In: MEDRADO, B. P.; REICHMANN, C. L. (Orgs.) Projetos e práticas na formação de professores de língua inglesa. João Pessoa: Editora da UFPB, p. $92-105$.

DICKINSON, L. (1994). Learner autonomy: what, why and how? In: LEFFA, V. J. Autonomy in language learning. Porto Alegre: Editora Universidade UFRGS, p. 2-12.

FIGUEIREDO, A. D. (2012). A geração 2.0 e os novos saberes. Sensos, v. 2, n. 1, p. 79-91.

FIGUEIREDO, E. Q.; CARDOSO, E. L. (2011). Blog: tecnologia para uma aprendizagem significativa da Língua Inglesa. Educação Unisinos, v. 15, n. 2, p. 158-165.

FONSECA, L. (2002). O uso de chats na aprendizagem de línguas estrangeiras. Caligrama, n. 7, p. 103-121.

FREIRE, P. (1996). Pedagogia da autonomia: saberes necessários à prática educativa. São Paulo: Paz e Terra.

GOMES, M. J. (2005). Blogs: um recurso e uma estratégia pedagógica. Actas do VII Simpósio Internacional de Informática Educativa SIIE05. Portugal: Escola Superior de Educação de Leiria, p. 311-315.

HEMAIS, B. (2010). Multimodalidade: enfoque para o professor de Ensino Médio. Janela de Ideias. Disponível em: http://www. letras.puc-rio.br/unidades\&nucleos/Janeladeldeias/b_linguagem.html. Acessado em março de 2020. 
KERCKHOFF, M. T. (2004). O blog como ferramenta para a reflexão crítica. In: MONTEIRO, M. J. P.; BARBOSA, H. G. (Orgs.) Cadernos de Letras 21 - interação em mídia e sala de aula. Rio de Janeiro: Universidade Federal do Rio de Janeiro, Ano 19, n. 21, p. 123-143.

KOZIKOSKI, E. P. L. (2007). A produção escrita em língua inglesa nas interfaces papel e blog. Dissertação de Mestrado em Linguística Aplicada e Estudos da Linguagem. São Paulo: Pontifícia Universidade Católica de São Paulo.

LEFFA, V. J. (2012). Ensino de línguas: passado, presente e futuro. Revista de Estudos da Linguagem. Belo Horizonte, v. 20, n. 2, p. 389-411.

LITTLE, D. (2003). Learner autonomy and second/foreign language learning. Disponível em:https://www.researchgate.net/ publication/259874624_Learner_autonomy_and_secondforeign_language_learning. Acesso em janeiro de 2020.

MACEDO, R. M. S.; KUBLIKOWSKI, I.; GRANDESSO, M. A. (2004). A interpretação em pesquisa qualitativa: a construção do significado. Conferência Internacional do Brasil de Pesquisa Qualitativa, Anais: I CIBRAPEQ. São Paulo: Tec Art Editora Ltda, p. $83-93$.

MARCUSCHI, L. A. (2005). Gêneros textuais emergentes no contexto da tecnologia digital. In: MARCUSCHI, L. A.; XAVIER, A. C. Hipertexto e gêneros digitais. (Orgs.) 2a ed. Rio de Janeiro: Lucerna, p. 13-67.

MELO, L. P. C. C. (2018). O processo de ensino aprendizagem da língua espanbola auxiliada pelas novas tecnologias digitais de informação e comunicação: uma proposta didático-pedagógica. Trabalho de Conclusão de Curso. João Pessoa, PB: Universidade Federal da Paraíba.

MELO, P. C. A. (2012). Google docs e a escrita criativa no ensino de Língua Inglesa. Dissertação de Mestrado. Universidade do Minho, Instituto de Educação.

MERHOLZ, P. (2002). Play with your words. Home Page. Disponível em: http://www.peterme.com/archives/00000205.htm

MIRANDA, G. L. (2007). Limites e possibilidades das TICs na educação. Sísifo - Revista de Ciências da Educação, n. 3, p. 41 -50.

MORAN, J. M. (2000). Ensino e aprendizagem inovadores com tecnologias. Informática na Educação: teoria e prática, v. 3, n. 1, p. $137-144$.

MOTTA-ROTH, D. De receptor de informação a construtor de conhecimento: o uso do chat no ensino de inglês para formando de Letras. In: LEFFA, V. J. (Org.) O professor de línguas estrangeiras - construindo a profissão. Pelotas: Educat, 2001, p. 175 -192.

NOYTIM, U. (2010). Weblogs enhancing EFL students' English language learning. Procedia Social and Behavioral Science, v. 2, p. $1127-1132$

NUNAN, D. (2003). Nine Steps to Learner Autonomy. Disponível em: http://www.su.se/polopoly_fs/1.84007.1333707257!/menu/ standard/file/2003_11_Nunan_eng.pdf. Acesso em: 18 de fevereiro de 2020, p. 193-204.

OLIVEIRA, M. C. S.; SANTOS, G. O. (2018). O uso das tecnologias no espaço escolar: transformações das TICs em recursos educativos. In: ALVES, I. M. A.; NETO, A. A. L. (Orgs.) O coordenador pedagógico em uma Educação a Distância sem distância. Salvador, BA: Edufba, p. 159-201.

OLIVEIRA, M. B. F.; SOUZA, A. S. (2018). Uma experiência com alunos de Letras em formação inicial: construindo um blog em sala de aula. The Especialist, v. 39, n. 3, p. 1-16.

PAIVA, V. L. M. O. (2001). Derrubando paredes e construindo comunidades de aprendizagem. In: LEFFA, V. J. (Org.) O professor de linguas estrangeiras - construindo a profissão. Pelotas: Educat, p. 193-209.

PAIVA, V. L. M. O. (2009). O ensino de língua estrangeira e a questão da autonomia. In: LIMA, D. C. (Org.). Ensino e aprendizagem de língua inglesa: conversas com especialista. São Paulo: Parábola Editorial, p. 31-38. 
PAIVA, V. L. M. O. (2010). Propiciamento (affordance) e autonomia na aprendizagem de língua inglesa. In: LIMA, D. C. Aprendizagem de língua inglesa: histórias refletidas. Vitória da Conquista: Edições UESB, p. 151-161.

PAIVA, V. L. M. (2019). Tecnologias digitais no ensino de línguas: passado, presente e futuro. Revista da Abralin, v. 18, n. 1, p. 2-26.

PÉREZ, M. P. (2012). El blog como instrumento de enseñanza-aprendizaje de idiomas. Espiral. Cuardenos del profesorado, v. 5, n. 9, p. 26-36

RAMOS, D. K. (2013). Perfil dos alunos de Licenciatura a distância e aspectos que contribuem para aprendizagem. Revista Reflexão e Ação, v. 21, n. esp., p.199-220.

REINDERS, H.; WHITE, C. (2016). 20 of autonomy and technology: how far have we come and where to next. Language Learning \& Technology, v. 20, n. 2, p. 143-154.

RODRIGUES, B. G. (2014). O perfil dos alunos ingressantes em um curso de Letras Inglês: expectativas e metas para a formação de professores. Revista L@el em (Dis)curso, v. 6, n. 2, p. 52-71.

SIDI, P. M.; CONTE, E. (2017). A hermenêutica como possibilidade metodológica à pesquisa em educação. Revista Ibero-Americana de Estudos em Educação, v. 12, n. 4, p. 1942-1954.

SILVA, M.; BRITO, S. (2013). Docência online no ensino superior: saberes docentes e formação continuada. Educação em Foco, v. 18, n. 1, p. $105-126$

SILVA, B. D.; PEREIRA, M. G. C. B. (2011). O papel da escola no combate à divisão digital. XI Congresso Luso Afro Brasileiro de Ciências Sociais. Universidade Federal da Bahia.

SOUZA, S. A. F. (1999) A Internet e o ensino de línguas estrangeiras. Linguagem \& Ensino, v. 2, n. 1, p, 139-172.

TAPSCOTT, D. (2008) Grow up digital: how the net generation is changing your world. MacGraw-Hill Education.

THEISEN, J. M. (2015). O letramento digital e a leitura online no contexto universitário. Tese de Doutorado. Pelotas, RS: Universidade Católica de Pelotas.

XAVIER, A. C. (2011) Letramento digital: impacto das tecnologias na aprendizagem da Geração Y. Calidoscópio, v. 9, n. 1, p. 3-14.

WARSCHAUER, M.; WHITTAKER, P. F. (1997). The Internet for English teaching: guidelines for teachers. The Internet TESOL Journal, v. 3, n. 10, p. 27-33.

WARSCHAUER, M.; ARADA, K; ZHENG, B. (2000). Laptops and inspired writing. Journal of adolescent \& adult literacy, v. 54, n. 3, p. 221-223.

Recebido: 6/4/2020

Aceito: 28/6/2021

Publicado: 14/9/2021 